\title{
Brain Laterality Demands that Two Human Species Exist: Evidence from Hemisity and Familaial Polariity
}

\author{
Bruce Eldine Morton \\ Department of Biochemistry and Biophysics, John A. Burns School of Medicine, University of Hawaii, Honolulu, Hawaii, USA
}

Email address:

bemorton@hawaii.edu

To cite this article:

Bruce Eldine Morton. Brain Laterality Demands that Two Human Species Exist: Evidence from Hemisity and Familaial Polariity. American Journal of Psychiatry and Neuroscience. Vol. 9, No. 2, 2021, pp. 31-37. doi: 10.11648/j.ajpn.20210902.12

Received: March 15, 2021; Accepted: March 29, 2021; Published: April 13, 2021

\begin{abstract}
The asymmetric location of functional units in the bilateral brain of animals and humans is the topic of brain laterality. So far, five lateralized functions have been discovered in humans: handedness, language ability, spatial skills, facial recognition, and emotion recognition. Recently a sixth asymmetric functional element bearing upon personality has been discovered. It is the larger side of the split bilateral anterior cingulate cortex (ACC). This appears to be the final output element of the brain's executive system, of which by logic there can be only one. Hemisity is the binary measure, based upon eight MRI validated biophysical and questionnaire methods. It determines whether a person was born with the larger side of the ACC on the right or left side of the brain. Which side of the ACC is largest varies among the general population in a seemingly random manner, yet with a genetic basis because true-breeding lineages exist. The corpus callosum of subjects was up to three times larger when the larger ACC was on the right, than on the left. There are over 30 measurable differences in in individual characteristics and behaviors of male or female persons whose larger ACC was on the right compared to those with it on the left. Familial Polarity refers to the mating outcomes of the four reproductive pairs: RM-LF; RF-LM; RM-RF; LM-LF. The first two "opposites attract" reproductive pairs were true breeding, producing offspring that were "like father like son, like mother like daughter". The offspring of the last two "same-same" pairs, were not true breeding, but rather their offspring were random in sex and hemisity. The simplest explanation for these results is that life on earth originated twice, once in deep sea vents and once in warm surface ponds. This resulted in two trees of life, one Patripolar (RM-LF) harem forming, the other Matripolar (RF-LM) territorial. Africa was the first subcontinent to evolve life to the level of primates, which upon docking populated the eastern hemisphere Eurasia in six waves. The first was the patripolar orangutans who settled in the empty far-east to become the orientals. Then next wave was the matripolar bonobos who stopped at India, and was followed by four later waves out of Africa. These alternating populations were immiscible and adversarial, with wars dominating their interfaces. This continues into the present day. Understanding Familial Polarity helps bring understanding and thus peace to the globe.
\end{abstract}

Keywords: Hemispheric Asymmetry, Corpus Callosum Size, Two True Breeding Species, Two Origins of Life, Two Trees of Life

\section{Introduction}

There are many differences between individuals and families which we have long overlooked or taken for granted. These also exist in wild animals, but up to now they have seemed meaningless. Similar differences exist between political parties and even nations. These, however, we have not been able to ignore.

In the case of differences between individuals, as the result of extensive research, reported in more than a dozen neuroscience publications, the following has been confirmed.
There are two cerebral hemispheres that are part of the human brain, one on the right, the other on the left. Based upon split brain results [6-8], it was early proposed that in the majority of humans, the two hemispheres are separate modules with opposite anatomical wiring orientations [14, 30]. The left is specialized in top-down, deductive cognitive dissection of local detail [4]. The right being specialized in bottom-up inductive perceptual synthesis of global structure $[5,8,30]$. That is, the left hemisphere of most right handed individuals manifests facilities for language, has an orientation toward for local detail, has object abstraction- 
identification abilities, and appears to possess a hypothesisgenerating, event "interpreter" [8]. In contrast, the right hemisphere has been demonstrated to excel in global analysis, object localizations, facial recognition, and spatial construction. Five recognized brain lateralizations that have been observed in humans are: handedness [13], language ability [31], spatial skills [12], facial recognition [15] and emotion recognition [10]. Although most have their language skills in the left and spatial skills on the right, in a minority of cases these can vary considerably as to their hemispheric locations [9].

Recently a sixth asymmetrical brain functional element bearing upon personality has been discovered by Morton and Rafto [21, 27]. It is the finding of existence of laterality within the split bilateral anterior cingulate cortex (ACC). This paired structure appears to be the final output element of the executive system of the bilateral vertebrate brain, which, by logic, there can only be one (The Buck Stops Here). Which side is the larger varies among the general population in a seemingly idiosyncratic manner, yet with a genetic basis because true-breeding lineages exist [24].

The earlier Hemisphericity work was converted into Hemisity, where the gradient idea of Hemisphericity was replaced by a binary measure [24]. Thus a person is inherently born either left brain oriented or right brain oriented. This binary definition has facilitated the development of eight hemisity measurement tools, four of which are binary biophysical assays [16, 18-20, 22], and four are behavioral questionnaires [32, 16, 19, 23, 33]. Crucially, these hemisity methods have been validated by the MRIbased discovery that the larger sided of the bilateral ACC is on the same side as one's hemisity [27], making MRI the primary standard for hemisity determination $(\mathrm{r}=0.96)$.

The asymmetric sides of the ACC are separated by the midline fissure of the brain. The larger side in Areas 24 and 24' appears to contain the element producing the final output of the executive system $[21,27]$. The relative sizes of the two sides of the ACC vary in a seemingly idiosyncratic manner [10]. There are at least 30 measurable differences in individual characteristics and behaviors between those with a larger executive final output element of the right compared to those with it on the left [26, 28].

This article reports that the sole executive center in humans must exist on one side of the brain or the other. Which side executive is on, confers unique traits to those individuals. Thus, if the executive center is on the left side where language and stressful emotions reside, left brainers of either sex will have behavioral traits more influenced by words and anxiety. If the executive center is on the right where the visualization and positive emotions reign, words and stressful emotions will have less impact on right brainers of either sex. This makes them bolder and more space oriented. These Familial Polarity trait biases have been found to supersede Male - Female biases in over thirty instances. This work explains why this occurs and how it demands the hypothesis that there are two different human races, one Patripolar, the other Matripolar.
This inevitably lead to the discovery of many behavioral similarities between right brainers (RMs and RFs) of the opposite sex, whose executive center for both is in the right hemisphere. There are also the corresponding many similarities between left brainers (LMs and LFs) of the opposite sex whose executive center is in the left hemisphere.

\section{The Many Behavioral Differences Based Upon Brain Laterality but Not Sex}

Thirty Familial Polarity behavioral differences, based upon Hemisity, have been found to exist between individuals of the same sex. Thirty Behavioral Polarity similarities in behavior have also been found between individuals of the opposite sex. These sixty similarities and differences fall into five categories: 1. Logical Orientation, 2. Type of Consciousness, 3. Fear Level and Sensitivity, 4. Social and Professional Orientation, 5. Pair-bonding Style and Spousal Dominance.

In the illustrations that follow, left brain-oriented male and female subjects here will be given names beginning with the letter L. Here they will be called Luke and Linda. Similarly, for those right brain oriented male or female subjects, names will be used that begin with the letter R. They will be called Robert and Ronna. For example, left brainers, Luke and Linda, tend to be oriented to the local scene. That is they see individual trees. While right brainers, Robert and Ronna, tend to be global in orientation, seeing the many different forests [4].

To illustrate how Familial Polarity works in practical terms, let's begin with the first category: Logical Orientation. Left brain-oriented individuals like Luke and Linda take a serious approach in solving their problems, sticking to the details of objective facts and using formal logic. They trust what has already been established to be the best.

In contrast, right brained individuals like Robert and Ronna tend to use a more playful, free-thinking approach to solving their problems, giving themselves freedom to use their imagination and intuition in a far-reaching global manner. They always seek new, better answers.

In terms or Type of Consciousness, the situation can be viewed so that left brain-oriented individuals, such a Luke and Linda, tend to be early morning persons who think in words, not pictures. Their daydreams aren't vivid and they usually forget their night time dreams. Somehow, this enables them to be comfortable in chaos and able to concentrate on many things at once, losing track of their surroundings while doing so.

Right brain-oriented persons, such as Robert and Ronna, are often late-night persons, who think in terms of picture images. Thus, they daydream vividly and often remember their dreams. Somehow, this causes them to concentrate on one thing in depth. Their concentration is disrupted if there is disorder and disorganization in their surroundings, yet they do not lose track of the surrounding larger picture while thinking. 
In terms of Fear Level and Sensitivity, left brain-oriented individuals such as Luke and Linda tend to carry a higher level of basic anxiety. This makes them more conservative and cautious in general, thus sensitive in relating to others. They avoid talking about their feelings because their underlying negative emotions are so close to the surface. These need to be kept suppressed because they seem to be overwhelming. This often causes them to use and become addicted to depressants such as alcohol.

Apparently because right brain-oriented persons such as Robert and Ronna, somehow are more insulated from their raw emotions, they can be more fearless, bold, and innovative than left brainers. This leaves them more freedom to form intense intimate relations with others. This allows them to deal with and discuss their own and other's feelings freely. They can allow themselves to enjoy experiencing and expressing their feelings and those of others. They may try to enhance their feelings with stimulants.

In Social and Professional Orientation left brain-oriented persons such as Luke and Linda continue to respond to their elevated access to emotions, especially fear, to minimize interactions with others. They do so by being independent, hidden, private, and indirect. They of course avoid evaluation by others and seek to avoid blame at all costs. They are unwilling to praise others, and often make themselves immune to the praise from others.

In contrast, right brain-oriented persons, such as Robert and Ronna, are sufficiently fearless as to be interdependent with others, being able to be open, public, and direct. They seek, rather than avoid, frank feedback about themselves from others. They are able to take the blame, blame themselves, and apologize to others. They are sufficiently secure as to be able to praise others. What others think of them is important to them.

For the last category: Pair-bonding Style and Spousal Dominance, left brain dominant individuals of either sex, like Luke and Linda, want to be left alone after having an upset with their spouse. In private, they can tolerate defiance in their mates, from whom they require little physical contact. They also find their spouse's mind difficult to read. They are not very romantic or sentimental, and more prefer monthly larger reassurances of love rather than day to day assurances. They think and listen quietly, and often think that their mate talks too much. They make lenient parents; whose kids tend to defy them.

Table 1. Thirty Examples where Familial Polarity Supersedes Sexual Orientation.

\begin{tabular}{|c|c|}
\hline Left brain oriented males and females & Right brain-oriented males and females \\
\hline \multicolumn{2}{|l|}{ LOGICAL ORIENTATION } \\
\hline Sees the important details. & Sees the big picture. \\
\hline Uses logic. & Imagines, convert concepts into contexts. \\
\hline Uses objective facts. & Uses intuition, feelings. \\
\hline Serious in approach. & Playful approach to solving problems. \\
\hline Prefers good old solutions & Prefers better, newer solutions. \\
\hline \multicolumn{2}{|l|}{ TYPE OF CONSCIOUSNESS } \\
\hline Daydreams are not vivid. & Has vivid daydreams. \\
\hline Often doesn't remember dreams. & Remembers dreams often. \\
\hline Thinks in words. & Thinks in mental images. \\
\hline Comfortable and productive in chaos. & Slowed by disorder and disorganization. \\
\hline Easily concentrates on many things at once. & Concentrates on one thing in depth. \\
\hline Often ignores surroundings when thinking. & Observant of surroundings when thinking. \\
\hline Often an early-morning person. & Often a late-night person. \\
\hline \multicolumn{2}{|l|}{ FEAR LEVEL AND SENSITIVITY } \\
\hline Conservative and Cautious. & Bold and Innovative. \\
\hline Sensitive in relating to others. & Intense in relating to others. \\
\hline Avoids talking about feelings. & Talks about feelings of self and others. \\
\hline Suppresses feelings as overwhelming. & Seeks to experience and express feelings. \\
\hline Would self-medicate with depressants. & Would self-medicate with stimulants. \\
\hline \multicolumn{2}{|l|}{ SOCIAL AND PROFESSIONAL ORIENTATION } \\
\hline Independent, hidden, private, and indirect. & Interdependent, open, public, and direct \\
\hline Avoids seeking evaluation by others. & Seeks frank feedback from others. \\
\hline Usually tries to avoid taking the blame. & Takes the blame, blame self, or apologizes. \\
\hline Does not praise others or work for praise. & Praises others, works for the praise of others. \\
\hline Left brain oriented males and females & Right brain-oriented males and females \\
\hline \multicolumn{2}{|l|}{ PAIR-BONDING STYLE AND SPOUSAL DOMINANCE } \\
\hline After an upset with spouse, needs to be alone. & After upset with spouse, needs closeness. \\
\hline Tolerates mate defiance in private. & Difficult to tolerate mate defiance in private. \\
\hline Needs little physical contact with mate. & Needs lots of physical contact with mate. \\
\hline Tends to be very romantic and sentimental. & Tends not to be very romantic or sentimental. \\
\hline Prefers monthly larger reassurances of love. & Likes daily assurances of mate's love. \\
\hline Thinks-listens quietly, minimizes talk. & Thinks-listens interactively, talks a lot. \\
\hline Does not read other's minds very well. & Good at knowing what others are thinking/ \\
\hline Often feels their mate talks to much. & Feels mate doesn't talk or listen enough. \\
\hline Lenient parent, kids tend to defy. & Strict, kids obey and work for approval. \\
\hline
\end{tabular}


The right brainers of either sex, like Robert and Ronna, need to have closeness with their spouses after having had an upset. They find it difficult to tolerate defiance from their mate in private. Then tend to be romantic and sentimental, needing daily reassurances of their mate's love. They are good at reading their mate's mind. They think and listen interactively with lots of talk. They often feel that their mates don't talk or listen to them enough. They are strict with their children, whom obey them and work for their approval. These results are represented in Table 1. Overall, each item had a probability of about $80 \%$.

There are several other differences between LPs and RPs that have been anecdotally reported. These include that LPs prefer unseasoned food, while RPs prefer spicy foods. LPs are more sensitive to aromas than RPs. LPs are more vulnerable to stress that RPs. The immune strength of LPs is weaker than that of RPs. LPs are often ill, while RPs are rarely ill. Medicine side effects affect LPs more than RPs. LPs tend to be thinner than RPs. LFs have smaller breasts than RFs. The non-erect length of LM penises is much longer than that of RMs. LPs may not live as long as RPs. Finally, and most importantly, RPs have been shown to have significantly larger corpus callosi than LPs.

Thus, it can be concluded that there are more than 30 behavioral differences which are completely unrelated to sex. Instead, these will be seen to be a part of what is called Familial Polarity.
Thus far, the behavioral similarities between RMs (right brain-oriented males) and RFs (right brain-oriented females), LMs (left brain-oriented males), and LFs (left brain-oriented females have not been recognized by science or the general public.

\section{Familial Polarity}

The next level of complexity within Familial Polarity comes with the opposite sex mate selection required for reproduction. That is, there are four possible breeding pairs: RM-LF, LM-RF, RM-RF and LM-LF. It has been observed that today the "opposites attract" possibilities: RM-LF and $\mathrm{LM}-\mathrm{RF}$ are found in the general population twice as often as the "same-same" RM-RF or LM-LF pairs.

What is the reproductive outcome from these four possible combinations $[23,25]$ ? It turns out that couples of opposite polarities breed true. That is, the offspring of RM-LF couples can be summarized as "like father, like son; like mother like daughter. Thus, in RM-LF patripolar families, the offspring are only RM sons or LF daughters. Similarly in the true breeding LM-RF matripolar families, again "like father-like son, like mother like daughter" holds true, where the son is always an LM and the daughters are all RFs. In contrast, the "same-same" polarity couples, RM-RF and LM-LF, the sex of the offspring is random, making those couples non true breeding. This is illustrated in Table 2 .

Table 2. Personality Traits Among The Familial Polarity Subtypes.

\begin{tabular}{lllll}
\hline TRAIT: & PATRIPOLAR & FAMILIES & MATRIPOLAR & FAMILIES \\
\hline Parental Sex & Male & Female & Female & Male \\
Hemisity & Right & Left & Right & Left \\
Corp. Callosal Size & Larger & Smaller & Larger & Smaller \\
Mind Orientation & Big Picture oriented & Important Details & Big Picture oriented & Important Details \\
Verbosity & Charismatic & Quiet, but Articulate & Charismatic & Quiet, but Articulate \\
Family Leadership & Most Dominant & Mate Supportive & Most Dominant & Mate Supportive \\
Parent LoveType & Conditional & Unconditional, & Conditional & Unconditional, \\
Parent Function & Sets Standards & Prevents Excess & Sets Standards & Prevents Excess \\
Child's Hemisity & Boys are Rights & Girls are Lefts & Girls are Rights & Boys are Lefts \\
Parental Status & Role Model & Serve the Child & Role Model & Serve the Child \\
Mating Behavior & Males select Disp-playing & Females court winning Males & Females select Displaying & Males court winning Females \\
& Females who are: & who are: & Males who are: & who are: \\
Mating Target & Intelligent, Funny Loyal, & Tall, Handsome Strongest, & Intelligent, Funny Loyal, & Beautiful, Thin, Big Breasted, \\
& Devoted, \& want to serve him & winners Smartest, Richest, & Devoted, \& want to serve her & Wide Hips Smartest, Richest \\
& & Socially powerful & Socially powerful, \\
\hline
\end{tabular}

There is evidence of ancient existence of whole societies where almost all males were RMs and almost all females were LFs $[23,25]$. These Patripolar populations have been found to be living next to entire nations of Matripolar populations where the majority of the males are LMs and most females are RMs. It was only at the population interfaces where non true breeding RM-RF and LM-LF couples were occasionally formed.

\section{Evidence That Life Evolved Twice}

A clear explanation for the existence of the true breeding patripolar and true breeding matripolar global populations is most consistent with the idea that life on earth evolved twice instead once. Once in hot geothermal deep see vents [3] and once in warm surface ponds [2]. This resulted in two separate human species from the evolution of two trees of life, not one. In the Patripolar tree all the males are RMs and all females are LFs [25, 28]. In the Matripolar tree of life, all the males are LMs and all the females are RFs. Table 3 briefly summarizes this with examples of occupants of the matripolar and patripolar trees of life.

It is logical to think that this level of evolution was present on the Pre-African continent, one of the several continents existing above sea level in the continental drift theory [32]. This appears to be the only place where evolution to the level 
of the higher primates had occurred. That is, before it docked

with Pre-Eurasian continent about 5 million years ago [29].

Table 3. THE TWO TREES OF LIFE AND THEIR REPRODUCTIVE STRATEGIES.

\begin{tabular}{lll}
\hline THE TWO TREES OF LIFE & PATRIPOLAR & MATRIPOLAR \\
\hline Reproductive Strategies & Harem Forming & Territorial \\
Reptiles & Alligators & Crocodiles \\
Dinosaurs & Anchiceratops & Tyranasaurus (female largest) \\
Birds & Chickens & Peafowl \\
Monotremes & Duck-billed Platypus & Spiny Ant-eater \\
Marsupials & Red Kangaroo & Northern Quoll \\
Placentals & Rat, Wolf, Deer, Lion & Mouse, Fox, Sheep, Tiger \\
Early Primates & Horse, Walrus, Elephant & Donkey, Elk, Hyena, Bear \\
Apes & Brown Lemur & Ring-tailed Lemur \\
Hominids & Gorillas, Orangutans & Chimps, Bonobos \\
\hline
\end{tabular}

Upon docking, it is here proposed [23-25] that eight waves of primate populations emerged out of Africa into the Eurasian eastern hemisphere. The first was wave of a patripolar orangutans, migrated into the empty far-east. This was followed by the matripolar bonobos who stopped at India. The mountain gorilla Neanderthals, another patripolar race, migrated to the Tigris-Euphrates river basin. They were followed by the matripolar dark faced Chimpanzees onto the Eastern Europe. These were followed by patripolar Neanderthal Lowland Gorillas going to the Rhine River. Lastly the matripolar white faced chimpanzees entered Western Europe to become the Cro-Magnons.

It is not surprising that the discovery of Familial Polarity uncovered evidence for two distinct human polarities At present the existence of two opposite primate reproductive strategies has yet to be recognized in apes by contemporary science, much less in humans. It is ironic that Familial Polarity was unknown to the writers of the Bible, and thus apparently escaped the eye of God.

We found that the corpus callosal size was significantly greater for RPs like Robert and Ronna, than in LPs like Luke and Linda. That is, RPs Robert and Ronna have up to three times greater interhemispheric communication than LP Luke and Linda did [21]. This size difference had earlier been predicted to exist to account for the dichotic deafness of LPs $[16,17]$.

Thus for humans, there actually are two basic types of men and two basic types of women. RPs of either sex (Robert and Ronna) have larger corpus callosi and are behaviorally more similar to each other than to the LPs of either sex (Luke and Linda) having smaller corpus callosi. The same goes for LPs of either sex (Luke and Linda) who are more similar to each other than they are to their same sex RPs (Robert and Ronna).

The Dmanisi Man, one of the first Caucasians, was found between the Caspian and Black Seas in the Caucasus near the ancient city of Tiblisi, Georgia, far from Africa. His era is dated at 1.7 million years ago. His cranial capacity was 700 $\mathrm{cm} 2$, only half of ours. Various stone flakes, scrapers, and chopping tools were found with these remains [1].

These alternating polarity races in the Eastern Hemisphere did not mix well. Patripolar cultures with dominant males and Matripolar cultures with dominant females created almost impassible social barriers between these true breeding polarities. This resulted in innumerable violent conflicts, where at death the patripolar victims from the Fatherland, called out: "Father! Father! Save Me! I'm Dying!

While matripolar victims of this deadly conflict from the Mother land, a death called out "Mother! Mother! Save Me! I'm Dying! [23, 25]

\section{Conclusion}

Across history, there were over twenty national conflicts where these killings occurred [23, 25]. In each of these in this list, the predominantly Matripolar populations are mentioned first. For example, the matripolar French vs. the patripolar Germans; Continuing with Russians and other Slavs vs. Germans; Jews vs. Germans; English vs. Scotts; Southern vs. Northern Irish; Italians vs. Sicilians; Spanards vs. Moors: Spanards vs. Basques; Jews vs. Arabs; Serbs vs. Albanians; Russians vs. Chechnyans; Armenians vs. Turks, Indians vs. Pakastanis; Indians vs. Sieks; Hutu Farmers vs. Watutsi Warriors; South vs. North Korea; South vs. North Vietnam; Philippinos vs. Moros; Romans vs. Greeks.

This has resulted in the eternal conflict between the two human species! Such conflicts could be resolved by understanding and applying Familial Polarity knowledge at all universe levels, starting with those within myself and within my spiritual life, moving on to those in my nuclear, and extended family, to conflicts with my neighbors, those within my community, my town or city, my state, my nation, and those within my world.

However, with increasing population growth and the emergence of cities, cultural mixing was inevitable. This resulted in the production of huge populations of non-true breeding stock from same-same polarity couples, followed by the breeding of those hybrids with other hybrids to produce some of the present amalgamated polarity population. The numbers of these non-true breeding hybrids appears so extensive that they appear to represent about one third of the current breeding populations [25]. That is, number of true breeding patripolar and matripolar couples combined is about twice that of random breeding hybrid couples. This has resulted in numerous social consequences resulting where one third of the population is Patripolar, one third is Matripolar, and one third is of mixed hybrids. The latter 
hybrids contain the great majority of known Dyslexics, Bisexuals, Homosexuals, Gothics, Pedophiles, and theoretically, Schizophrenics [23, 25].

Thus, knowledge of Familial Polarity [24, 25. 28] provides a powerful tool that brings real understanding to the seemingly inexplicable individual and familial differences now existing. The consequences of knowledge of Familial Polarity are so simple and lawful, that they could easily be taught. If all citizens were introduced to the concept of Familial Polarity, it could bring significant improvement to society in general.

\section{References}

[1] Balter, M, Gibbons, A. (2002) Were 'little people' the first to venture out of Africa, Science, 297, 26-27.

[2] Ben, K. D., Pearce, R. E., Pudritz, R. E., Semenov, D. A., Henning, T. K. (2017). Origin of the RNA world: The fate of nucleobases in warm little ponds. Proc. Nat. Acad. Sci. 114, 11327-11332.

[3] Dodd, M. S., Papineau, D., Grenne, T., et al. (2017). Evidence for early life in earths oldest hydrothermal vent precipitates. Nature 543, 60-64.

[4] Fink GR, Halligan PW, Marshall JC, Frith CD, Frackowiak RS \& Dolan RJ. (1996). Where in the brain does visual attention select the forest and the trees. Nature, 336, 766-767. https://doi.org/10.1017/S1344517717000376.

[5] Floegel, M, \& Kell, CA (2017). Functional hemispheric asymmetries during the planning and manual control of virtual avatar movements. PLos One, 12, 78790. https://doi.org/10.1371/journal.pone.0185152.

[6] Gazzanaga MS, Bogen, JE, Sperry RW. (1967). Some functional effects of sectioning the cerebral commissures in man. Proceedings of the National Academy of Sciences, USA 48, 1765-1769.

[7] Gazzaniga MS. (1989) Organization of the human brain. Science 245, 947-952.

[8] Gazzaniga MS. (2000). Cerebral specialization and interhemispheric communication; Does the corpus callosum enable the human condition? Brain, 123, 1293-1326.

[9] Haberling IS, Bazakova-Trajkov G \& Corballis MC. (2011). Collosal tracts and patterns of hemispheric dominance: A combined fMRI and DTI study. Neuroimage 54, 779786.https://doi.org/10.1016/j.neuroimage2010.09.072.

[10] Huster RJ, Westerhausen R, Kreuder F, Schweiger E, Whittling W. (2017). Morphologic asymmetry of the human anterior cingulate cortex. Neuroimage, 34, 888-895. https://doi.org/10.1016/j.neuroimage2010.09.072.

[11] Innes, R, Burt DM, Birch YK, \& Hausmann M, (2015). A leftward bias no matter how you look at it: Revisiting the emotional chimeric face task as a tool for measuring emotion lateralization Laterality $28, \quad 1-19$, https://doi.org/10.1080/1357650X.2015.1117095.

[12] Kang X, Herron TJ, Ettlinger M \& Woods DL, (2015). Hemispheric asymmetries in cortical and subcortical anatomy. Laterality, 658-684.
https://doi.org/10.1080/1357650X.2015,1032975.

[13] Knect S, Drager B, Deppe M, Bobe L, Lohman H, Floel a, Henningsen H. (2000). Handedness andhemispheric dominance in healthy humans. Brain, 123, 2512-2518. https://doi.org/10.1093/brain/123.12.2512.

[14] Levy, J. (1969) Possible basis for the lateral specialization of the human brain. Nature, 224, 614-5.

[15] Morita T, Saito DN, Ban M, Shimada K, Okamoto Y, Kosaka H, Naito E. (2017). Self-face recognition shares brain regions active during proprioceptive illusion in the right inferior fronto-parietal superior longitudinal fasciculus III network. Neuroscience 348, 288-301. https://doi.org/10.1016/neuroscience.2017.02.031.

[16] Morton, B. E. (2001). Large individual differences in minor ear output during dichotic listening. Brain And Cognition, 45, 229-237.

[17] Morton, B. E. (2002). Outcomes of hemisphericity questionnaires correlate with unilateral dichotic deafness. Brain and Cognition, 49, 63-72.

[18] Morton, B. E. (2003a). Phased mirror tracing outcomes correlate with several hemisphericity measures. Brain and Cognition, 51, 294-304.

[19] Morton, B. E. (2003b). Two-hand line-bisection task outcomes correlate with several measures of hemisphericity. Brain and Cognition, 51, 305-316.

[20] Morton, B. E. (2003c). Asymmetry questionnaire outcomes correlate with several hemisphericity measures. Brain and Cognition, 51, 372-374.

[21] Morton, B. E. and Rafto, S. E. (2006). Corpus callosal size is linked to dichotic deafness and hemisphericity, not sex or handedness. Brain and Cognition, 62, 1-8.

[22] Morton, B. E. and Rafto, S. E. (2010). Behavioral laterality advance: Neuroanatomical Evidence for the Existence of Hemisity. Personality and Individual Differences, 49, 34-42

[23] Morton, B. E. (2011). Neuroreality. Megalith Books, Doral, $F L$.

[24] Morton B. E. (2012a). Left and right brain-oriented hemisity subject show opposite behavioral preferences. Frontiers in Physiology 3: 407. doi: 10.3389/fphys.2012.00407.

[25] Morton, B. E. (2012b). Two Human Species Exist. Megalith Books, Doral, FL.

[26] Morton B. (2013) E. Behavioral laterality of the brain: Support for the binary construct of hemisity. Frontiers in Psychology, 4: 683. doi: 10.3389/fpsyg.2013.00683.

[27] Morton, B. E. and Rafto, S. E. (2017b). Executive laterality: Evidence from hemisometry, hemisity, and MRI. Universal Journal of Psychology. 5 (6) 244-252.

[28] Morton, B. E. (2020). Brain executive laterality and hemisity. Personality Neuroscience. 3, 1-10 (2020) doi: 10l.1017/pen.2020.6.

[29] Ofer, B. Y., Cohen, A, B., (2001). From Africa to Eurasia: early dispersals. Quaternary International 75, 19-28.

[30] Sperry RW (1982). Some effects of disconnecting the cerebral hemispheres. Science, 217, 1223-1226. 
[31] Stroobant N, Bujis D, \& Vingerhoets G. (2009). Variations in brain lateralization during various language tasks: A functional transcranial Doppler study. Behavioral and Brain Research. 199, 190-196. https://doi.org/10.1016/jlbbr.2008.11.040.

[32] Wegner, Alfred (1912) Die Herausbilding der Grossformen der Erdinde (Kontente und Ozean), auf Geophysikalisher
Grundlage. Peterman's Geophisiche Grundlage. 63, 185-309 (1911).

[33] Zenhausern R. (1978). Imagery, cerebral dominance, and style of thinking: A unified field model. Bulletin [of the Psychonomic Society, 12, 381-384. https://doi.org/10.3758/BF03329714. 